ISSN: 1812-1217

Eman A Mustafa

BSc, MSc (Lect)

\section{Bacteriological Study on Tooth Brushes}

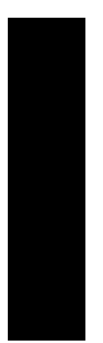

\author{
Department of Dental Basic Science \\ College of Dentistry, University of Mosul
}

\begin{abstract}
Aims: To determine if the tooth brushes in a regular use can become contaminated with microorganisms and to investigate if the microorganisms were present with a packaged brushes. Materials and methods: Thirty synthetic tooth brushes were used in this study. Ten adults each was supplied with new tooth brush of the same type and brand together with identical tubes of fluoridated tooth paste. After three weeks, subjects were requested to follow their normal hygiene practices, twenty new tooth brushes from two manufacturers were also enrolled in this study. All brushes were collected, decapitated and cultured in different culture media to identify aerobic and anaerobic microorganisms present in each tooth brush. Results: The result showed that various microorganisms can grow on used tooth brushes, Staphylococcus epidermidis were isolated from all used tooth brushes except one, $\alpha$ hemolytic Streptococci, yeasts (Candida albicans), Pseudomonas spp., Bacillus subtilis and Escherichia coli were isolated from $70 \%, 60 \%, 50 \%, 30 \%$ and $20 \%$ of the used brushes respectively. Proteus spp. and Enterobacter spp. were isolated from 10\% of tooth brushes while Corynebacteria, Aerococci and Moraxella catarrhalis were isolated from $40 \%$ of used tooth brushes. Anaerobic bacteria (Peptococcus spp., Veillonella spp. and Peptostreptococcus spp.) were isolated from 30\%, 20\% and 10\% of the used brushes respectively. Eleven from twenty unused brushes were contaminated; while other nine were apparently bacteria free. Conclusions: It is concluded that used tooth brushes were found to harbour microorganisms and it cannot be determined whether or not the brushes were contaminated when new.

Key words: Tooth brushes, microorganisms.

Mustafa EA. Bacteriological Study on Tooth Brushes. Al-Rafidain Dent J. 2009; 9(2): 268-272.

Received: 22/4/2008 Sent to Referees: $27 / 4 / 2008$

Accepted for Publication: 31/8/2008
\end{abstract}

\section{INTRODUCTION}

Tooth brushes may be heavily contaminated with microorganisms. Those microorganisms are not only from oral cavity $^{(1)}$, but also from environment where tooth brushes are kept. Microorganisms from kept environments can also be introduced; these include enteric bacteria dispersed via aerosols from toilet flushing or from contaminated fingers and skin commensals, pseudomonas emanating from the bathroom and other wet areas ${ }^{(2)}$.

The relationship between bacteria in tooth brushing patients with periodontitis was studied ${ }^{(3)}$. Thirty periodontal patients were selected for the brushing study and nine patients who have extraction participated. Blood samples were drawn during the fourth minutes of brushing and immediately after extraction procedures. Bacteria found in blood samples from the brushing group were compared with bacterial culture from the extraction group. nine extraction cases.

Svanberg $^{(4)}$ found that tooth brushes and tooth paste can be heavily infected with Streptococcus mutans for 24 hours after usage. This study also suggested that brushing with a contaminated brush introduces new microorganisms, while simultaneously reducing existing normal flora.

The aim of this study is to investigate the microbial contamination of used tooth brushes and to determine whether microorganisms were present with a packaged brushes.

\section{MATERIALS AND METHODS}

Thirty synthetic tooth brushes were used in this study. They were divided into two groups, first group included ten tooth brushes of the same brand and type (Nice manufactures by Nice House of Plastics, Iraq) were used by ten adults with healthy oral conditions who did not show any signs of gingival inflammation and had no apparently decayed teeth (all decayed were filled) as examined by a dentist who confirm their healthy oral conditions before the beginning of the study. All adults were given an identifications of fluoridated tooth paste (Signal, by Unilever Mashreq, 
Egypt). All individuals were asked to follow their normal oral hygiene practices for three weeks and do not take any antimicrobial drugs during this period. Finally, each tooth brush was collected in a sterile container and processed within 18 hours of its last use.

The second group included twenty new tooth brushes from two manufactures (Nice) and (Oral B Manufactured by Acument House Ware Industry, China).

All tooth brushes were decapitated under sterile conditions (using a sterile gloves and nippers) and each head was transferred into a sterile vial containing 10 $\mathrm{ml}$ of Brain Heart Infusion Broth (Oxoid) and the vials were incubated at $37^{\circ} \mathrm{C}$ for 24 hours. The following plates were then inoculated by the incubated brain heart broth and incubated at $37^{\circ} \mathrm{C}^{(5)}$ :

1. Bloodagar(two replicates for each vial).

2. Sabouraud dextrose agar ${ }^{(6)}$.

3. Chocolate agar.

4. MacConkey agar (Oxoid).

A plate of blood agar, chocolate agar Sabouraud dextrose agar and MacConkey agar were incubated aerobically for 48 hours, while the other blood agar plate was incubated anaerobically using anaerobic jar with gas pack (Oxoid, England), $\mathrm{H}_{2}$ and $\mathrm{CO}_{2}$ generator envelop which was activated simply by adding $10 \mathrm{ml}$ of distilled water, then jar was closed properly and incubated at $37^{\circ} \mathrm{C}$ for 48 hours ${ }^{(7,8)}$.

Predominant colonies were identified in each plate, pure cultures were obtained and biochemical tests were done on each microorganism for identification at the genus level ${ }^{(9)}$.

\section{RESULTS}

The results of this study showed that there were several types of microorganisms isolated from used brushes (Table 1). No brush was bacteria -free. Staphylococci were found on all except one of the tooth brushes and were often numerically dominant. $\alpha$ - hemolytic Streptococci, yeasts (all identified as Candida), Pseudomonas spp., B. subtilis and Esch. coli were identified in $70 \%, 60 \%, 50 \%, 30 \%$ and $20 \%$ of tooth brushes respectively. Proteus spp. and Enterobacter spp. was identified in $10 \%$ of tooth brushes. While, each of Aerococci,
Corynebacteria and $M$. catarrhalis were identified in $40 \%$ of tooth brushes. Anaerobic bacteria such as Peptococcus spp., Veillonella spp. and Peptostreptococcus spp. were identified in $30 \%, 20 \%$ and $10 \%$ of tooth brushes respectively.

Tests were also carried out on twenty unused tooth brushes, as shown in Table (2). There were a new tooth brushes directly from their packages, nine tooth brushes from the first company (A) were contaminated with Staph. epidermidis or/and B. subtilis while eight of ten from another company (B) showed no growth. Therefore even though nine of ten used brushes demonstrated Staph. Epidermidis. It can not be determined at this point, whether or not the brushes were contaminated when "new".

\section{DISSCUSION}

These findings showed that most tooth brushes were extensively contaminated with a variety of microorganisms. These results are comparable to those recorded by other investigators ${ }^{(1,3,10)}$. Tooth brushes may become contaminated by microorganisms with use, and a contaminated tooth brush can be the cause of reinfection of a person with pathogenic bacteria ${ }^{(11.12)}$.

In this study, Staph. epidermidis was one of the mostly found microorganisms on tooth brushes, their presence may be related to the fact that most of the individuals used their finger during post brushing rinsing of their tooth brushes. Candida albicans could have originated from either the skin or the mouth while the origin of Coliform, Aerococci and B. subtilis could be environmental ${ }^{(2)}$. Moist environment is more conducive to the growth of microorganisms than open air, so tooth brushes must not be stored in closer container and should be kept away from sink or toilet to prevent air born contamination. Other microorganisms like Veillonella spp., Peptococcus spp., M. catarrhalis and Peptpstreptococcus spp. could be also originated from the mouth ${ }^{(13)}$.

No tooth brush was found to harbor Lactobacilli or black - pigmented gram negative anaerobic rods, which are potential oral pathogens. 
Table (1): Types of microorganisms isolated on various media from used tooth brushes.

\begin{tabular}{|c|c|c|c|c|c|c|c|c|c|c|}
\hline \multirow{2}{*}{ Type of microorganisms } & \multicolumn{10}{|c|}{ Subject (brush) } \\
\hline & 1 & 2 & 3 & 4 & 5 & 6 & 7 & 8 & 9 & 10 \\
\hline Staph. epidermidis & + & + & + & + & + & + & + & + & - & + \\
\hline$\alpha$ hemolytic streptococci & + & + & & + & & + & - & + & + & + \\
\hline Candida albicans & + & - & + & - & + & + & - & + & - & + \\
\hline Esch. coli & - & - & - & - & - & + & - & + & - & - \\
\hline Proteus spp. & - & - & - & - & - & + & - & - & - & - \\
\hline Enterobacter spp. & - & - & + & - & - & - & - & - & - & - \\
\hline Pseudomonas spp. & + & - & + & & - & & + & + & - & + \\
\hline Aerococcus spp. & - & + & - & + & + & & + & - & - & - \\
\hline $\begin{array}{l}\text { Corynebacterium spp. (diphthero- } \\
\text { ids) }\end{array}$ & - & + & - & + & + & - & - & - & + & - \\
\hline Moraxella catarrhalis & + & + & & + & - & - & + & - & - & - \\
\hline Peptococcus spp. & - & - & - & - & - & - & + & - & + & + \\
\hline Peptostreptococcus spp. & - & - & - & - & - & + & - & - & - & - \\
\hline Veillonella spp. & + & - & - & - & + & - & - & - & - & - \\
\hline Bacillus subtilis & - & - & - & + & + & - & - & + & - & - \\
\hline
\end{tabular}


Table (2): Contamination of unused brushes from two company.

\begin{tabular}{ll}
\hline Brush number & \multicolumn{1}{c}{ Contamination } \\
\cline { 2 - 2 } & \multicolumn{1}{c}{ Company A* } \\
\hline 1 & Staph. epidermidis, Bacillus subtilis \\
3 & Staph. epidermidis \\
4 & Staph. epidermidis \\
5 & Staph. epidermidis, Bacillus subtilis \\
6 & Bacillus subtilis \\
7 & Staph. epidermidis \\
8 & Staph. epidermidis \\
9 & Staph. epidermidis \\
10 & No growth \\
\hline & Bacillus subtilis \\
\hline 1 & \multicolumn{1}{c}{ Company B** } \\
2 & No growth \\
3 & No growth \\
4 & No growth \\
5 & Candida albicans \\
6 & No growth \\
7 & No growth \\
\hline 0 & Staph. epidermidis \\
pany B: OralB (manufactured by Acument House Ware Industry, China) \\
\end{tabular}

\section{CONCLUSIONS}

According to the result; aerobic and obligate anaerobes were recovered from tooth brushes after brushing. Some of unused brushes directly from their packages were also found to be contaminated, therefore it can not be determined whether or not the brushes were contaminated when new.

\section{REFERENCES}

1. Malmberg E, Birkhed D, Norvenius $\mathrm{G}$, Noren JG, Dahlen CT. Microorganisms on tooth brushes at day care centers. Acta. Odontol. Scand. 1994; 52: $93-98$.

2. Scott E, Bloom field SF, Barlow CG. An investigation of microbial contamination in the home. J. Hyg. 1982; 89: $279-293$.

3. Verran J, Leahy -Gil martin AA. Investigation into the microbial contamination of tooth brushes. Microbios. 1996; 85: $231-238$.

4. Svanberg M. Contamination of toothpaste and tooth brushes by Streptococcus mutans. Scan. J. Dent. Res. 1978; 86: $412-414$. 
5. Glass RT, Lare MM. Tooth brush contamination a potential health risk? Quintess. Int.1986; 17: 39-42.

6. Cruckshank R, Duguid TP, Marmion BP, Swain RHA. Medical microbiology. Volume 11, 12 edition, Churchill, Livingstone, England. 1975; P. 136.

7. Atlas RM, Parks LC, Brown AE. Laboratory Manual of Experimental Microbiology. Mosby Company, London. 1995; Pp: 33 - 34.

8. Morello JA, Mizer HE, Granato PA. Laboratory Manual and Work Book in Microbiology. $7^{\text {th }}$ edition. McGrawhill, London. 2003; P: 223.

9. Konenman EW, Allen SD, Janada WM, Schreckenberger PC, Winn WCW. Color Atlas and Text Book of
Diagnostic Microbiology. 15 edition, J.B. Lippincott. Raben Publisher, Philadelphia, U.S.A. 1997.

10. Kozai K, Iwai T, Miura K. Residual contamination of tooth - brushes by microorganisms. J. Dent. Child. 1989; 56: $201-204$.

11. Cobb CM. Tooth brushes as cause of repeated infections of the mouth. Boston Med. Surg. J. 1920; 183: 263 264.

12. Glass RT, Shapiro S. Oral inflammatory disease and the tooth brush. $J$. Okla. Dent. Assoc. 1992; 82: 30 - 32.

13. Samaranayake LP. Essential Microbiology for Dentistry. $2^{\text {nd }}$ edition, Churchil, Livingstone Publisher, London, 2002; Pp: 207 - 216. 